\title{
Risk factors associated with mortality in veteran population following transtibial or transfemoral amputation
}

\author{
Barbara Bates, MD; ${ }^{1-2 *}$ Margaret G. Stineman, MD; ${ }^{3-4}$ Dean M. Reker, PhD, RN $;^{5-6}$ Jibby E. Kurichi, MPH; $^{3}$ \\ Pui L. Kwong, MPH \\ ${ }^{1}$ Samuel S. Stratton Department of Veterans Affairs (VA) Medical Center (VAMC), Albany, NY; ${ }^{2}$ Department of \\ Physical Medicine and Rehabilitation, Albany Medical College, Albany, NY; ${ }^{3}$ Department of Physical Medicine and \\ Rehabilitation, University of Pennsylvania, Philadelphia, PA; ${ }^{4}$ VA Center for Health Equity Research and Promotion, \\ Philadelphia, PA; ${ }^{5}$ Kansas City VAMC, Kansas City, MO; ${ }^{6}$ The University of Kansas Medical Center, Kansas City, KS
}

\begin{abstract}
This study explored medical conditions associated with mortality among veterans following transfemoral amputation, transtibial amputation, or hip disarticulation. We applied logistic regression models to identify clinical factors associated with mortality postoperatively. The participants included patients with lower-limb amputations $(n=2,375)$ who were discharged from Veterans Health Administration hospitals between October 1, 2002, and September 30, 2003. Most (98.9\%) were male. We measured cumulative in-hospital, 3-month, and 1-year mortality. The results were 180 in-hospital deaths, 368 by 3 months, and 634 by the 1 -year postsurgical amputation date. Those who had perioperative systemic sepsis (odds ratio $=4.28$, $95 \%$ confidence interval $=2.87-6.39$ ) had more than a fourfold increased likelihood of in-hospital mortality. Congestive heart failure, renal failure, and liver disease were significantly associated with mortality at all time periods. Metastatic cancer was associated only at 3 months and 1 year. We concluded that high medical complexity and mortality rates attest to the need for careful medical oversight during the postacute rehabilitation period.
\end{abstract}

Key words: aging, amputation, artificial limbs, comorbidity, hospital mortality, mortality, regression analysis, rehabilitation, sepsis, veterans.

\section{INTRODUCTION}

Peripheral vascular disease (PVD) and diabetes mellitus are the most common reasons for lower-limb amputations [1-11]. Diabetes mellitus increases an individual's risk for amputation twelve- to fifteenfold and accounts for over 50 percent of all nontraumatic amputations in the United States annually [12-13]. Glycemic control, systolic blood pressure, microvascular complications (such as neuropathy, retinopathy, and nephropathy), and history of stroke have been found to be independent predictors of amputation [13].

Abbreviations: BIRLS = Beneficiary Identification Records Locator Subsystem; $\mathrm{CI}=$ confidence interval; $\mathrm{COPD}=$ chronic obstructive pulmonary disease; ICD-9-CM = International Classification of Diseases, 9th Revision, Clinical Modification; OR = odds ratio; PTF = Patient Treatment File; PVD = peripheral vascular disease; $\mathrm{SD}=$ standard deviation; $\mathrm{VA}=$ Department of Veterans Affairs; VAMC = VA medical center; VHA = Veterans Health Administration.

* Address all correspondence to Barbara Bates, MD, Associate Chief of Staff for Quality Management; Samuel S. Stratton VAMC, 113 Holland Avenue, Albany, NY 12208; 518626-5817; fax: 518-626-5467. Email: barbara.bates@va.gov DOI: $10.1682 / J R R D .2006 .03 .0030$ 
Mortality following a lower-limb amputation is quite high. Thirty-day mortality rates range from 6.3 to 42.3 percent [14-15]. Pohjolainen, Alaranta, and Wikstrom reported that 25.5 percent of patients with lower-limb amputations in Finland died within 2 months of the amputation and nearly 40 percent within 1 year [7]. Survival rates at 2 to 5 years are also poor, with over 50 percent of patients dying at 2 years and roughly 70 percent by 5 years $[1,6-8,14-15]$.

Little has been written about the implications of high mortality rates in a population of patients typically considered for rehabilitation following surgery. This article explores the factors associated with mortality following transtibial or transfemoral amputation or hip disarticulation and considers the affect on the rehabilitation decision-making process.

\section{METHODS}

\section{Description of Data Sources}

To capture diagnostic information from different aspects of the patient care process, our analyses included four separate database sources of administrative data from the Veterans Health Administration (VHA). The first source was the Patient Treatment File (PTF) database, including the International Classification of Diseases, 9th Revision, Clinical Modification (ICD-9-CM) codes relevant to the entire inpatient hospital stay. One variable in the PTF is the principal diagnosis (Dx Prime), and nine additional variables are available to express secondary diagnoses. Another variable describes the diagnosis most responsible for the major part of the patient's full length of stay (Dx Lsf). The PTF record associated with the hospitalization within which the primary amputation surgery occurred is called the "index PTF" and is the baseline patient record.

The second source was a database that includes multiple individual "bed section" records that capture diagnostic information collected on patients receiving care on particular services (surgery, intensive care unit, medicine, etc.) during the entire hospital stay. Each bed section record includes a variable describing the medical condition most responsible for the length of stay in the bed section and four variables for secondary diagnoses directly related to care received during that treatment period. Patients typically have multiple bed section records for each hospitalization (associated with the index PTF). Each bed section record has admission and discharge dates which, when linked, correspond to the full PTF stay.

The third database source describes outpatient visits. During each outpatient visit, a principal diagnosis intended to describe the reason for the visit is coded (Dx Lsf) in one variable. Nine additional variables are available for secondary diagnostic information.

Finally, the fourth database was the Department of Veterans Affairs (VA) Beneficiary Identification Records Locator Subsystem (BIRLS) death file. The PTF identifies patients who died in a VA hospital. The BIRLS database contains records of all beneficiaries, including veterans whose survivors applied for death benefits [16]. Combining the BIRLS with the PTF will provide a thorough list of the veterans with lower-limb amputations who died. Neither the PTF nor the BIRLS provides specific cause of death information as indicated by an ICD-9-CM code.

\section{Database Development}

We combined ICD-9-CM codes from the PTF, bed section, and outpatient files to distinguish between diagnoses that likely contributed directly to amputation, otherwise known as etiological conditions, and concurrent conditions less likely to be directly related to the amputation, or comorbidities. The etiological and comorbid conditions were captured with ICD-9-CM codes in each PTF case record. Two physician authors established the list of etiological diagnoses in conjunction with a literature review and the conditions in the Dx Prime and Dx Lsf variables of the PTF [2,5,17-18]. Clinically, similar ICD-9-CM codes were grouped into 11 etiological categories (Table 1).

Rather than seeking to assign a single etiological cause for the amputation, we considered the cause of limb loss to be multifactorial, recognizing that many clinical conditions interact and ultimately lead to limb loss. Groups of ICD-9CM codes evidencing trauma, systemic sepsis, skin breakdown, device infection, local significant infection, previous amputation complication, diabetes mellitus (types 1 and 2), chronic osteomyelitis, problems with peripheral circulation, congenital disorders, and cancer of the lower limb were included as etiologies. The etiological variables captured diagnostic information from the index PTF and all outpatient files where the date of contact fell within 3 months preceding the index PTF admission date. The etiological variables also included diagnostic codes from any bed section record where the admission date occurred no earlier than 3 months preceding the index PTF admission date. 
Table 1.

Conditions contributing to etiology of amputation and their International Classification of Diseases, 9th Revision, Clinical Modification (ICD-9CM) codes.

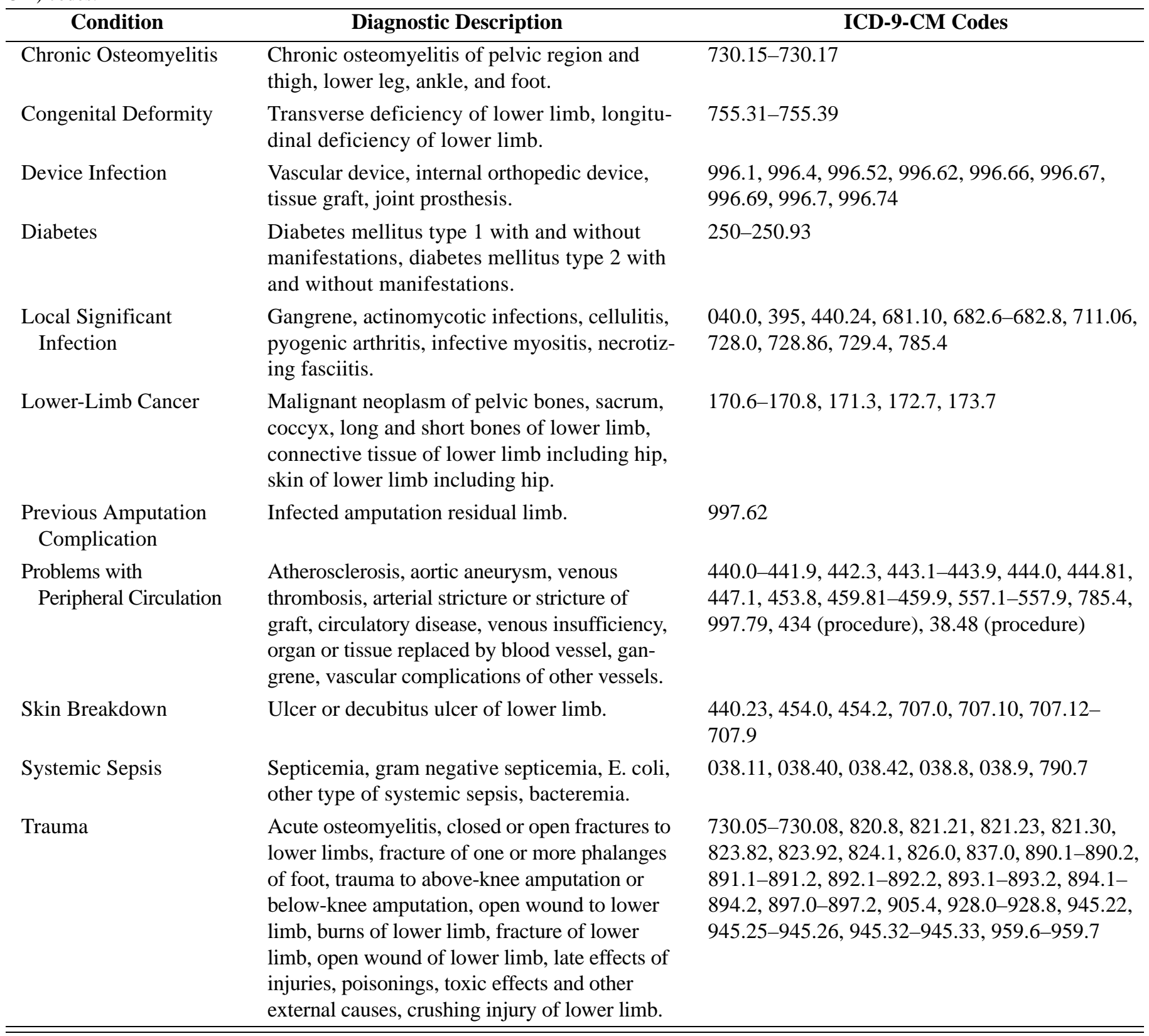

Codes from bed sections with admission dates after the surgical date were not included.

Comorbidity was expressed by the Elixhauser Measure. The Elixhauser consists of 31 separate measures expressing each condition separately by combining sets of related ICD-9-CM codes [19]. The conditions include ICD9-CM codes describing congestive heart failure, arrhythmias, valvular disease, pulmonary circulation disease, PVD, hypertension, hypertension with complication, paralysis, other neurological disorders, chronic obstructive pulmonary disease (COPD), diabetes mellitus, diabetes mellitus with complication, hypothyroidism, renal failure, liver disease, peptic ulcer disease, acquired immune deficiency syndrome, lymphoma, metastatic cancer, solid tumor without metastases, rheumatoid arthritis, coagulopathy, obesity, weight loss, fluid and electrolyte disorders, chronic blood 
loss anemia, deficiency anemias, alcohol abuse, drug abuse, psychoses, and depression. Although less commonly reported in the literature than the Deyo version of the Charlson index [20], the Elixhauser Measure includes a broader array of diagnostic conditions. Some evidence has shown that it is a superior predictor of mortality [21]. Diabetes mellitus, diabetes mellitus with complication, and PVD were not included among the Elixhauser conditions, since they were already included as contributing etiological conditions. An individual could have multiple etiological or comorbid diagnoses. Each etiological or comorbid condition was coded “ 1 ” if present and “ 0 ” if absent.

\section{Case Inclusions}

This study included all 2,375 patients who were admitted to 100 VA medical centers (VAMCs) around the nation for transtibial or transfemoral amputation and hip disarticulation and had acute hospital discharge dates between October 1, 2002, and September 30, 2003. The hospital stay at the time the surgical amputation occurred represented the "index stay." Patients were excluded if they had amputations that involved toes only or had a record of a previous lower-limb amputation within the 12 months preceding the index surgical amputation. Surgical amputation that includes transtibial, transfemoral, and hip disarticulation was captured with the surgical ICD-9-CM procedure codes 84.10, 84.13-84.19, and 84.91 [15].

\section{Approach to Modeling}

Using the statistical analyses, we developed a multivariate model to determine the clinical factors most associated with mortality following amputation. The analyses began with a series of cross-tabulations between each explanatory variable and mortality at three time-points: in-hospital, 3-month, and 1-year. The presence versus absence of each etiological and comorbid condition was expressed as a dichotomous indicator. Sociodemographic variables included age and sex. Age was entered as a series of segmented dummy variables, with 50 years and younger as the reference group. Females were the reference group for sex. Variables that predicted mortality were included in multivariate models only when expected values were five or more individuals. No case from our sample had an ICD-9-CM code for obesity as defined by the Elixhauser Measure. We used logistic regression modeling to control for multiple variables simultaneously and to compute 95 percent confidence interval (CI) around each odds ratio (OR). We assessed the impact of increasingly detailed information on the likelihood of mortality through a series of fixed multiple logistic regressions, where sets of clinically related variables were entered in sequential models. Amputation level and sociodemographic variables were entered together as a block, followed by contributing etiological diagnoses, and finally by comorbidities. The $C$ statistic assessed model performance corresponding to the area under the receiver operating characteristic curve [22]. $C$ statistics closer to 1.0 denote greater model prediction power. We applied the Hosmer-Lemeshow goodness-offit statistic to test-fit the data to the model. Statistical significance at $p<0.05$ was used to reject the hypothesis of fit [23]. Analyses were performed with SAS Version 9.1 (SAS Institute, Cary, North Carolina). The $p$-values were two-sided, with $p<0.05$ being considered statistically significant. An association is statistically significant at this level if its 95 percent CI does not include 1.0.

\section{RESULTS}

\section{Study Population}

Among the 2,375 veterans included in the study, 98.9 percent were male, average age was 67.3 years (standard deviation $[\mathrm{SD}]=11.0$ ), and average length of stay was 28.6 days (SD $=52.3$ ). Over one-half or 59.5 percent of the amputations were transtibial, 39.7 percent were transfemoral, and 0.7 percent were hip. Four cases had an unknown level of amputation. Their level of amputation was imputed using hot-deck methods [24]. The in-hospital mortality rate was 7.6 percent, the 3-month mortality rate was 15.5 percent, and the 1-year mortality rate was 26.7 percent. Table 2 characterizes the population by indicating mortality prevalence associated with each candidate predictor variable. Table 3 shows the adjusted OR for each explanatory variable according to the completely saturated models of in-hospital, 3-month, and 1-year mortality. The $C$ statistic for the model predicting in-hospital mortality based on age, sex, and level of amputation was 0.66. With the addition of the contributing etiological conditions, it increased to 0.73 . With the addition of the Elixhauser conditions, the $C$ statistic increased to 0.80. $C$ statistic increases were similar for the 3-month and 1-year regressions; however, as shown by Table 3, model performance was slightly better for inhospital than for 3-month and 1-year mortalities. 
Table 2.

Characteristics of study sample $(N=2,375)$ according to mortality.

\begin{tabular}{|c|c|c|c|c|c|}
\hline \multirow{2}{*}{ Characteristic } & \multirow{2}{*}{ Prevalence } & \multirow{2}{*}{ Survival } & \multicolumn{3}{|c|}{ Mortality } \\
\hline & & & In-Hospital & 3-Month & 1-Year \\
\hline Age (mean \pm SD) & $67.3 \pm 11.0$ & $66.0 \pm 10.9$ & $70.0 \pm 10.3$ & $71.4 \pm 10.3$ & $71.0 \pm 10.6$ \\
\hline Male & 2,349 (98.9) & $1,722(73.3)$ & $178(7.6)$ & $362(15.4)$ & 627 (26.7) \\
\hline Female & $26(1.1)$ & $19(73.1)$ & $2(7.7)$ & $6(23.1)$ & 7 (26.9) \\
\hline \multicolumn{6}{|l|}{ Level of Amputation, No. (\%) } \\
\hline Transfemoral & 942 (39.7) & $607(64.4)$ & 109 (11.6) & $211(22.4)$ & $335(35.6)$ \\
\hline Hip Disarticulation & $16(0.7)$ & $11(68.8)$ & $5(31.3)$ & $5(31.3)$ & 5 (31.3) \\
\hline \multicolumn{6}{|l|}{ Nonchronic Etiologies, No. (\%) ${ }^{*}$} \\
\hline Device Infection & $266(11.2)$ & $204(76.7)$ & $21(7.9)$ & $40(15.0)$ & $62(23.3)$ \\
\hline Local Significant Infection & $1,850(77.9)$ & 1,337 (72.3) & $141(7.6)$ & $296(16.0)$ & $513(27.7)$ \\
\hline Trauma & $326(13.7)$ & $253(77.6)$ & $16(4.9)$ & $30(9.2)$ & $73(22.4)$ \\
\hline \multicolumn{6}{|l|}{ Chronic Etiologies, No. (\%) ${ }^{*}$} \\
\hline Chronic Osteomyelitis & $157(6.6)$ & 129 (82.2) & $5(3.2)$ & $9(5.7)$ & $28(17.8)$ \\
\hline Diabetes Mellitus Type 1 & $416(17.5)$ & $310(74.5)$ & $32(7.7)$ & $48(11.5)$ & $106(25.5)$ \\
\hline Diabetes Mellitus Type 2 & $1,546(65.1)$ & $1,151(74.5)$ & $96(6.2)$ & $213(13.8)$ & $395(25.5)$ \\
\hline Problems with Peripheral Circulation & 2,063 (86.9) & $1,487(72.1)$ & $161(7.8)$ & $334(16.2)$ & $576(27.9)$ \\
\hline \multicolumn{6}{|l|}{ Chronic Conditions, No. (\%) } \\
\hline Acquired Immune Deficiency Syndrome & $17(0.7)$ & $13(76.5)$ & $2(11.8)$ & $3(17.6)$ & $4(23.5)$ \\
\hline Alcohol Abuse & $130(5.5)$ & $105(80.8)$ & $9(6.9)$ & $17(13.1)$ & $25(19.2)$ \\
\hline Arrhythmias & $382(16.1)$ & $226(59.2)$ & $52(13.6)$ & $97(25.4)$ & $156(40.8)$ \\
\hline Drug Abuse & $54(2.3)$ & $46(85.2)$ & $2(3.7)$ & $3(5.6)$ & $8(14.8)$ \\
\hline Fluid and Electrolyte Disorders & 447 (18.8) & $287(64.2)$ & $61(13.6)$ & $105(23.5)$ & $160(35.8)$ \\
\hline Hypertension & $1,390(58.5)$ & $1,047(75.3)$ & $85(6.1)$ & $186(13.4)$ & $343(24.7)$ \\
\hline Hypertension with Complication & $13(0.5)$ & $9(69.2)$ & $1(7.7)$ & $2(15.4)$ & $4(30.8)$ \\
\hline Hypothyroidism & 89 (3.7) & $57(64.0)$ & $8(9.0)$ & $15(16.9)$ & $32(36.0)$ \\
\hline Liver Disease & $81(3.4)$ & $54(66.7)$ & $11(13.6)$ & $21(25.9)$ & $27(33.3)$ \\
\hline Lymphoma & $9(0.4)$ & $5(55.6)$ & $2(22.2)$ & $4(44.4)$ & $4(44.4)$ \\
\hline Metastatic Cancer & $32(1.3)$ & $14(43.8)$ & $5(15.6)$ & $16(50.0)$ & $18(56.3)$ \\
\hline Other Neurological Disorders & $72(3.0)$ & $46(63.9)$ & $11(15.3)$ & $16(22.2)$ & $26(36.1)$ \\
\hline Paralysis & 93 (3.9) & $77(82.8)$ & $4(4.3)$ & $8(8.6)$ & $16(17.2)$ \\
\hline Peptic Ulcer Disease with Bleeding & $35(1.5)$ & $28(80.0)$ & $3(8.6)$ & $5(14.3)$ & $7(20.0)$ \\
\hline Psychoses & $164(6.9)$ & $124(75.6)$ & $13(7.9)$ & $26(15.9)$ & $40(24.4)$ \\
\hline Pulmonary Circulation Disease & $17(0.7)$ & $7(41.2)$ & $4(23.5)$ & $6(35.3)$ & $10(58.8)$ \\
\hline Renal Failure & 410 (17.3) & $242(59.0)$ & $59(14.4)$ & $98(23.9)$ & $168(41.0)$ \\
\hline Rheumatoid Arthritis & $32(1.3)$ & $24(75.0)$ & $1(3.1)$ & $4(12.5)$ & $8(25.0)$ \\
\hline
\end{tabular}


JRRD, Volume 43, Number 7, 2006

Table 2. (Continued)

Characteristics of study sample $(N=2,375)$ according to mortality.

\begin{tabular}{|c|c|c|c|c|c|}
\hline \multirow{2}{*}{ Characteristic } & \multirow{2}{*}{ Prevalence } & \multirow{2}{*}{ Survival } & \multicolumn{3}{|c|}{ Mortality } \\
\hline & & & In-Hospital & 3-Month & 1-Year \\
\hline \multicolumn{6}{|c|}{ Chronic Conditions, No. $(\%)^{*}$ (continued) } \\
\hline Valvular Disease & $111(4.7)$ & $61(55.0)$ & 15 (13.5) & $30(27.0)$ & $50(45.0)$ \\
\hline Weight Loss & $109(4.6)$ & $74(67.9)$ & $8(7.3)$ & 25 (22.9) & $35(32.1)$ \\
\hline
\end{tabular}

Note: Only one person was coded with a congenital deformity, and no persons were coded with either lower-limb cancer or obesity.

*Cases associated with etiologies and chronic conditions do not sum to total sample size because a person can have multiple conditions.

$\mathrm{SD}=$ standard deviation.

\section{Etiological Factors}

In-hospital mortality and likelihood of mortality at all subsequent time periods were most strongly associated with systemic sepsis in the perioperative period after the adjustment for sociodemographic differences, level of amputation, and comorbidities. Likelihood of mortality was not significantly increased according to any of the other etiological factors. In-hospital rates of mortality were significantly lower among patients identified as having diabetes mellitus type 2 and 3-month mortality rates were lower for those coded with chronic osteomyelitis. Two of the eleven etiological category variables, congenital deformity (one case) and lower-limb cancer (zero cases), were not analyzed in the multivariate models because of insufficient prevalence.

\section{Level of Amputation}

After adjusting for age, etiological factors, and comorbidities, we found almost a thirteenfold increased risk of in-hospital mortality among patients with hip disarticulation compared with those with transtibial amputation (OR = 12.94; 95\% CI = 3.36-49.86). In-hospital mortality was also elevated for veterans with transfemoral amputations compared with transtibial (OR $=2.52$; $95 \%$ CI $=1.75-3.63)$. No association was found between increased likelihood of 1-year mortality and hip disarticulation, whereas mortality risk remained elevated among those with transfemoral amputations compared with transtibial $(\mathrm{OR}=2.00 ; 95 \% \mathrm{CI}=1.61-2.48)$.

\section{Comorbidities}

Using logistic regression models, we found that adjusted in-hospital, 3-month, and 1-year mortalities were significantly elevated among patients with evidence of con- gestive heart failure, renal failure, and liver disease. Threemonth mortality likelihood was significantly increased with coagulopathy. In-hospital and 3-month mortality rates were higher among those who experienced in-hospital fluid and electrolyte disorders. Those patients with documented metastatic cancer had higher 3-month and 1-year mortality rates. Among those with solid tumor without metastases and those with COPD, 1-year mortality, but not 3-month or inhospital, was elevated. Patients with hypertension listed among their diagnoses had a reduced likelihood of inhospital, 3-month, and 1-year mortality.

\section{Age}

Unadjusted risk of mortality increased with age. Strength of this association decreased progressively with the addition of more diagnostic details. The association between in-hospital mortality and age was no longer statistically significant after adjusting for level of amputation, etiological contributing factors, and comorbid conditions. In contrast, the association between longerterm mortality and age diminished but remained statistically significant among the oldest veterans with amputations. When compared with those aged 70 or younger, veterans with amputations aged 71 and older had higher adjusted 3-month mortality risks. Only those aged 81 and older had higher adjusted 1-year mortality risks. We found nearly a fourfold increased risk of mortality at 1 year, even after removing the effects of perioperative medical complexity among those over the age of 86 ( $\mathrm{OR}=3.86 ; 95 \% \mathrm{CI}=1.91-7.79)$. Among those over the age of $86(\mathrm{OR}=6.86 ; 95 \% \mathrm{CI}=2.53-18.59)$, close to a sevenfold increase in likelihood of mortality at 3 months was found. 
Table 3.

Odds ratio (OR) with 95\% confidence interval (CI) for likelihood of mortality in total population $(N=2,375)$.

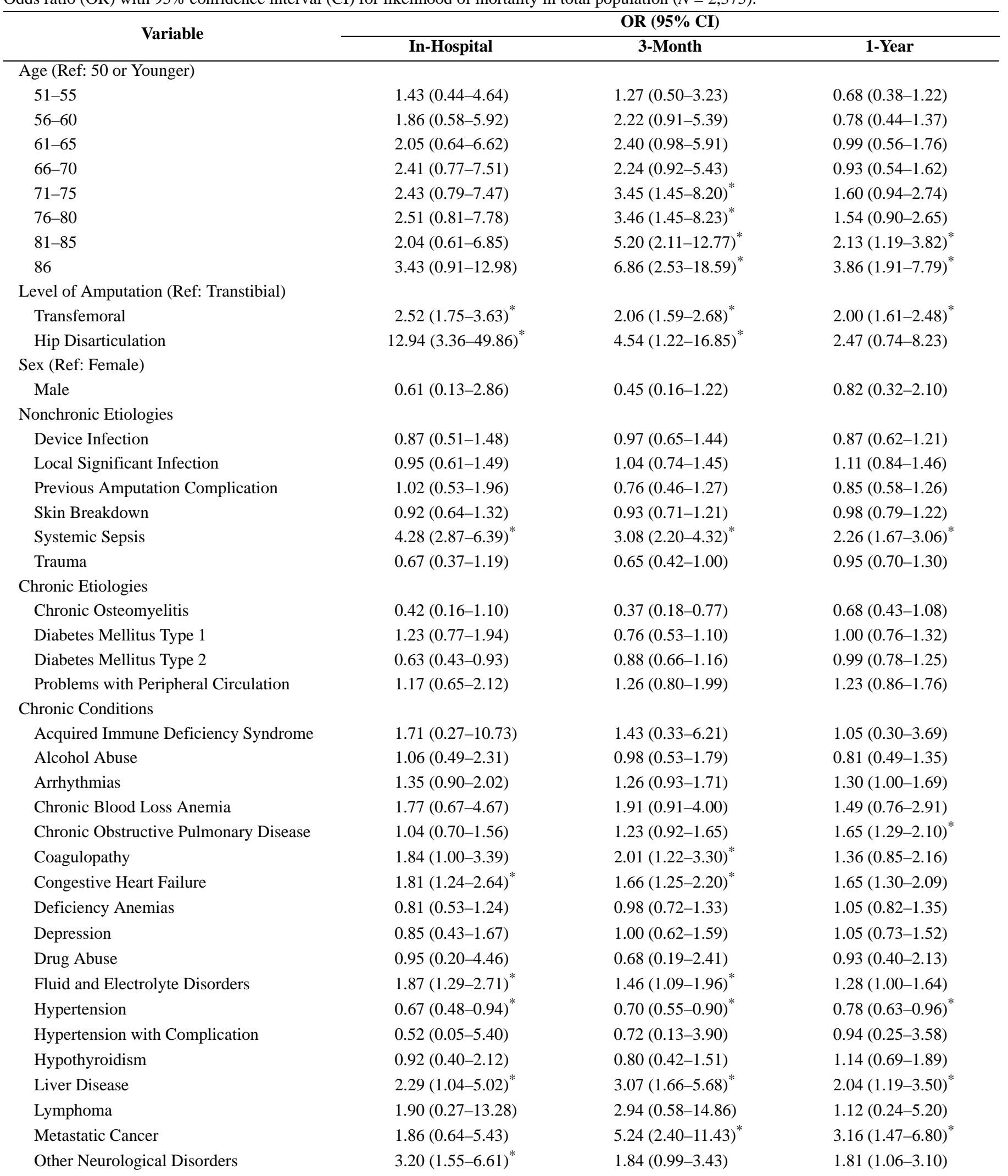


JRRD, Volume 43, Number 7, 2006

Table 3. (Continued)

Odds ratio (OR) with 95\% confidence interval (CI) for likelihood of mortality in total population $(N=2,375)$.

\begin{tabular}{llll}
\hline \multicolumn{1}{c}{ Variable } & \multicolumn{1}{c}{ OR (95\% CI) } \\
\cline { 2 - 4 } Chronic Conditions (continued) & In-Hospital & 3-Month & 1-Year \\
$\quad$ Paralysis & $0.42(0.14-1.23)$ & $0.48(0.22-1.07)$ & $0.55(0.31-1.00)$ \\
$\quad$ Peptic Ulcer Disease with Bleeding & $1.71(0.47-6.27)$ & $1.41(0.50-3.94)$ & $0.92(0.38-2.25)$ \\
$\quad$ Psychoses & $1.10(0.57-2.11)$ & $1.08(0.66-1.76)$ & $0.89(0.59-1.35)$ \\
$\quad$ Pulmonary Circulation Disease & $2.16(0.57-8.22)$ & $2.00(0.64-6.26)$ & $2.31(0.79-6.79)$ \\
$\quad$ Renal Failure & $2.29(1.55-3.38)^{*}$ & $1.87(1.38-2.53)^{*}$ & $2.21(1.71-2.85)^{*}$ \\
$\quad$ Rheumatoid Arthritis & $0.26(0.03-2.26)$ & $0.64(0.19-2.13)$ & $0.89(0.37-2.18)$ \\
$\quad$ Solid Tumor Without Metastases & $1.51(0.84-2.73)$ & $1.19(0.76-1.86)$ & $1.94(1.36-2.78)$ \\
$\quad$ Valvular Disease & $1.09(0.57-2.07)$ & $1.31(0.80-2.15)$ & $1.50(0.98-2.32)$ \\
$\quad$ Weight Loss & $0.61(0.27-1.39)$ & $1.28(0.75-2.16)$ & $1.15(0.73-1.82)$ \\
C Statistic for Full Model & 0.80 & 0.77 & 0.75 \\
Hosmer-Lemeshow $p$-Value & 0.99 & 0.60 & 0.09 \\
${ }^{*}$ Statistically significant, $p=0.05$. & & & \\
Ref = reference (for group). & & & \\
\hline \hline
\end{tabular}

\section{DISCUSSION}

The in-hospital mortality rate found in this study is consistent with previously reported data; however, the 1-year survival rate was slightly higher in this population than in other VA reports and among those treated in the private sector (Table 4) [6,14,25-27]. Some trend has shown that over the years, survival rates have improved; however, based on a post hoc random-effects model, survival rates were not statistically significantly higher than those found in the other studies. The trend toward higher survival rates found in our study may be related to overall improvements in technology that were not available to clinicians when the earlier studies were conducted. It may also be that VA patients have better access to the full continuum of services ranging from emergent to long-term and nursing home care than private sector patients. Perhaps veterans who have a lower-limb amputation performed in the VA healthcare system are provided a more coordinated and vertically integrated approach to postacute services, which in turn may affect longer-term survival.

Systemic sepsis was the single most predictive etiological factor of mortality in our analysis. In a recent retrospective study at an academic tertiary care center, Aulivola et al. found that cardiac complications were the leading cause of death within 30 days following lower-limb amputation (10/35), followed by sepsis (5/35) and pneumonia (4/35) [26]. The 30-day mortality rate was 8.6 percent in this population, and patients with sepsis requiring guillotine amputation had a significantly higher 30-day mortality rate of 14.3 percent [26].

Age has been noted to predict mortality following nontraumatic lower-limb amputation [15,25]. However, in this analysis, except for very elderly patients, the importance of age as a factor declined with the addition of more diagnostic details. This finding suggests that the associated burden of illness, rather than age, most influences mortality among persons with lower-limb amputation. Comorbidities appeared to affect mortality rates postamputation in logical ways. Severe progressive conditions including renal failure, liver disease, and congestive heart failure predicted mortality at all three postoperative time-points. Unsurprisingly, fluid and electrolyte disorders during the hospitalization were associated with higher rates of in-hospital and 3-month mortality. Also reasonable was that the presence of metastatic cancer and solid tumor without metastases significantly increased likelihood of mortality at 3 months and 1 year, respectively.

The comorbid conditions found to be positive predictors of mortality are consistent with other studies. Collins et al. identified COPD, renal dysfunction, and poor functional status preoperatively as indicators for 30-day mortality [25]. Using VA National Surgical Quality Improvement Program data, O'Hare et al. found that mortality rates within 30 days following lower-limb nontraumatic amputation were quite 
Table 4.

Comparison of survival rates (\%) over time within Department of Veterans Affairs (VA) and non-VA sectors.

\begin{tabular}{|c|c|c|c|c|c|c|c|c|c|}
\hline \multirow[b]{2}{*}{ Author } & \multirow{2}{*}{$\begin{array}{c}\text { Year } \\
\text { Published }\end{array}$} & \multirow{2}{*}{$\begin{array}{c}\text { Data } \\
\text { Collected }\end{array}$} & \multirow{2}{*}{$\begin{array}{c}\text { VA } \\
\text { Population }\end{array}$} & \multicolumn{3}{|c|}{ In-Hospital (\%) } & \multicolumn{3}{|c|}{ 1-Year (\%) } \\
\hline & & & & Transtibial & Transfemoral & $\begin{array}{c}\text { Hip } \\
\text { Disarticulation }\end{array}$ & Transtibial & Transfemoral & $\begin{array}{c}\text { Hip } \\
\text { Disarticulation }\end{array}$ \\
\hline Bates et al. [1] & 2006 & $2002-2003$ & Yes & 95.3 & 88.4 & 68.7 & 79.2 & 64.6 & 68.7 \\
\hline Feinglass et al. [2] & 2001 & 1991-1995 & Yes & 93.7 & 86.7 & - & 77.0 & 59.0 & - \\
\hline Mayfield et al. [3] & 2001 & 1992 & Yes & 93.0 & 88.9 & - & - & - & - \\
\hline Aulivola et al. [4] & 2004 & 1990-2001 & No & 94.3 & 83.5 & - & 74.5 & 50.6 & - \\
\hline Rommers et al. [6] & 1997 & 1991-1992 & No & $89.0^{*}$ & $89.0^{*}$ & - & - & - & - \\
\hline Pohjolainen et al. [7] & 1989 & 1984-1985 & No & - & - & - & 69.9 & 53.8 & 71.4 \\
\hline
\end{tabular}

*Survival was not reported by level of amputation.

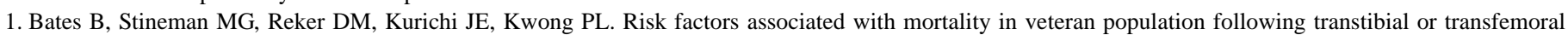
amputation. J Rehabil Res Dev. 2006;43(7):917-28.

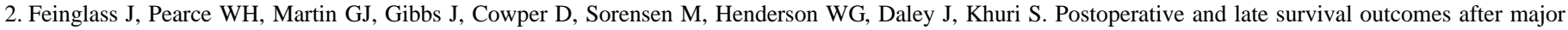
amputation: Findings from the Department of Veterans Affairs National Surgical Quality Improvement Program. Surgery. 2001;130(1):21-29. [PMID: 11436008]

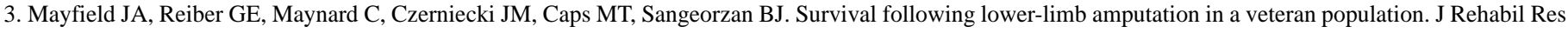
Dev. 2001;38(3):341-45. [PMID: 11440266]

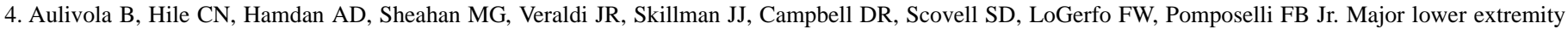
amputation: Outcome of a modern series. Arch Surg. 2004;139(4):395-99. [PMID: 15078707]

5. Pohjolainen T, Alaranta H. Ten-year survival of Finnish lower limb amputees. Prosthet Orthot Int. 1998;22(1):10-16. [PMID: 9604271]

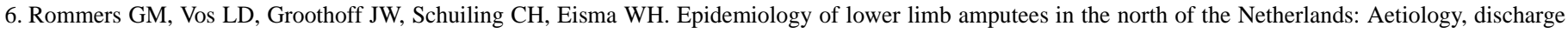
destination and prosthetic use. Prosthet Orthot Int. 1997;21(2):92-99. [PMID: 9285952]

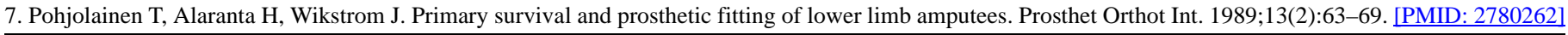

high in patients on dialysis and that patients with even moderate renal insufficiency were at higher mortality risk than those with mild or no renal disease [27]. Kantonen et al. likewise found the presence of coronary artery disease and renal dysfunction to be associated with higher postoperative mortality rates [28]. The presence of complex medical conditions such as congestive heart failure, hypothyroidism, renal failure, coagulopathies, and fluid and electrolyte disorders signals the need for vigilant acute and longer-term medical management of patients with a lower-limb amputation. In one VA study, nearly 50 percent of the veterans with congestive heart failure died within 1 year [15].

Our findings that diabetes mellitus and hypertension appeared protective regarding mortality are clinically counterintuitive, but consistent with the findings of others. Patients who have these conditions documented in their administrative records have significantly lower rates of mortality [29-30]. Perhaps the coding of more severe acute and complicating conditions among the seriously ill takes precedence. Or, perhaps because these patients have chronic conditions, they are monitored more carefully, and when problems do arise, they are caught early and do not develop into fatal issues.
Our finding that hip disarticulation was strongly associated with in-hospital mortality, but not longer-term mortality, suggests that the need for this high level of amputation is signaling greater perioperative acuity and complications but may not be associated with comorbidities associated with mortality. Other studies have shown lower survival rates for more proximal amputation levels [8,31-32]. Pohjolainen et al. reported survival rates at 2 months of 83.3 percent for patients with transtibial amputations, dropping to 67.7 percent for transfemoral [7]. By 1 year, survival was 69.9 and 53.8 percent, respectively [7].

For rehabilitation of patients following a nontraumatic lower-limb amputation, care teams need a better understanding of mortality risk in the months and years following surgery to target services to this population. For patients at high risk of mortality within 6 months to 1 year, early intervention and rehabilitation goals that focus on appropriate mobilization, activities of daily living, and quality-of-life issues become critical. A better understanding of mortality risk factors would help care teams develop improved, integrated treatment plans for frail dysvascular patients at high mortality risk. A balance between early intervention and longer-term goals is the key. 
Evidence suggests that with early and aggressive rehabilitation following stroke, patients improved faster, which led to higher functioning levels more quickly, even though the control group caught up to them within 9 months [33]. For a patient with a recent amputation, our data showed that 3 months or 1 year is a large percentage of the patient's remaining life span and that rehabilitation must focus on appropriate activities that help patients function more quickly, thus adding quality to their remaining lifetime. While mortality following a lower-limb amputation for vascular disease is high, many patients who survive the immediate postoperative period receive a prosthesis [1,7,9,34-38]. These patients function reasonably well, at least in the short term. When one considers the high-mortality and long-term outcomes, optimal postoperative care following a lower-limb amputation requires close collaboration and a team approach involving surgery, medicine, and rehabilitation to identify the most appropriate treatments, goals, and location of care.

While numerous clinical practice guidelines exist for the poststroke population [39-42], review of the literature found none for the postamputation population. Providing early and aggressive rehabilitation following lower-limb amputation makes intuitive sense, but evidence is lacking and should be a focus of future research. Development of a rehabilitation clinical pathway for patients with amputation would be one possible method of ensuring early postamputation involvement of rehabilitation professionals and could help in the careful analysis of the impact of early intervention. Because our sample was primarily male, the degree to which findings would generalize to female is unknown.

\section{CONCLUSIONS}

High mortality rates attest to the frailty of the postamputation veteran population. Rehabilitation strategies targeted to enhance the function of this larger population of patients with amputations need to address the shortened life span of many of these patients, and rehabilitation goals need to be adjusted accordingly. Careful medical oversight in the weeks and months following a nontraumatic amputation is critical in helping these patients achieve their highest functioning levels.

\section{ACKNOWLEDGMENTS}

This material is based upon work supported in part by the National Institutes of Health (R01 HD042588). It is also supported by resources and the use of facilities at the Samuel S. Stratton VAMC, Albany, New York, and the Kansas City VAMC, Kansas City, Missouri.

The opinions and conclusions of the authors are not necessarily those of the sponsoring agencies.

The authors have declared that no competing interests exist.

\section{REFERENCES}

1. De Luccia N, Pinto MA, Guedes JP, Alters MT. Rehabilitation after amputation for vascular disease: A follow-up study. Prosthet Orthot Int. 1992;16(2):124-28. [PMID: 1408671]

2. Dillingham TR, Pezzin LE, MacKenzie EJ. Limb amputation and limb deficiency: Epidemiology and recent trends in the United States. South Med J. 2002;95(8):875-83. [PMID: 12190225]

3. Ebskov LB. Level of lower limb amputation in relation to etiology: An epidemiological study. Prosthet Orthot Int. 1992;16(3):163-67. [PMID: 1491949]

4. Humphrey LL, Palumbo PJ, Butters MA, Hallett JW Jr, Chu CP, O'Fallon WM, Ballard DJ. The contribution of noninsulin-dependent diabetes to lower-extremity amputation in the community. Arch Int Med. 1994;154(8):885-92.

[PMID: 8154951]

5. Mayfield JA, Reiber GE, Maynard C, Czerniecki JM, Caps MT, Sangeorzan BJ. Trends in lower limb amputation in the Veterans Health Administration, 1989-1998. J Rehabil Res Dev. 2000;37(1):23-37. [PMID: 10847569]

6. Nehler MR, Coll JR, Hiatt WR, Regensteiner JG, Schnickel, GT, Klenke WA, Strecker PJ, Anderson MW, Jones DN, Whitehill TA, Moskowitz S, Krupski WC. Functional outcome in a contemporary series of major lower extremity amputations. J Vasc Surg. 2003;38(1):7-14. [PMID: 12844082]

7. Pohjolainen T, Alaranta H, Wikstrom J. Primary survival and prosthetic fitting of lower limb amputees. Prosthet Orthot Int. 1989;13(2):63-69. [PMID: 2780262]

8. Pohjolainen T, Alaranta H. Ten-year survival of Finnish lower limb amputees. Prosthet Orthot Int. 1998;22(1):10-16. [PMID: 9604271]

9. Rommers GM, Vos LD, Groothoff JW, Eisma WH. Clinical rehabilitation of the amputee: A retrospective study. Prosthet Orthot Int. 1996;20(2):72-78. [PMID: 8875999]

10. Rommers GM, Vos LD, Groothoff JW, Schuiling CH, Eisma WH. Epidemiology of lower limb amputees in the 
north of the Netherlands: Aetiology, discharge destination and prosthetic use. Prosthet Orthot Int. 1997;21(2):92-99. [PMID: 9285952]

11. Global Lower Extremity Amputation Study Group. Epidemiology of lower extremity amputations in centres in Europe, North America and East Asia. The Global Lower Extremity Amputation Study Group. Br J Surg. 2000;87(3):328-37. [PMID: 10718803]

12. Morris AD, MacAlpine R, Steinke D, Boyle DI, Ebrahim AR, Vasudev N, Stewart CP, Jung RT, Leese GP, MacDonald TM, Newton RW. Diabetes and lower-limb amputations in the community: A retrospective cohort study. Diabetes Care. 1998;21(5):738-43. [PMID: 9589233]

13. Selby JV, Zhang D. Risk factors for lower extremity amputation in persons with diabetes. Diabetes Care. 1995;18(4): 509-16. [PMID: 7497861]

14. Feinglass J, Pearce WH, Martin GJ, Gibbs J, Cowper D, Sorensen M, Henderson WG, Daley J, Khuri S. Postoperative and late survival outcomes after major amputation: Findings from the Department of Veterans Affairs National Surgical Quality Improvement Program. Surgery. 2001; 130(1):21-29. [PMID: 11436008]

15. Mayfield JA, Reiber GE, Maynard C, Czerniecki JM, Caps MT, Sangeorzan BJ. Survival following lower-limb amputation in a veteran population. J Rehabil Res Dev. 2001; 38(3):341-45. [PMID: 11440266]

16. Kubal JD, Webber S, Cowper DC, Waight S, Hynes DM. A primer on major U.S. mortality databases used in health services research. In: VIREC Insights. No. 5. Hines (IL): Department of Veterans Affairs Information Resource Center; 2000.

17. Collins TC, Beyth RJ. Process of care and outcomes in peripheral arterial disease. Am J Med Sci. 2003;325(3): 125-34. [PMID: 12640288$]$

18. Dillingham TR, Pezzin LE, MacKenzie EJ. Incidence, acute care length of stay, and discharge to rehabilitation of traumatic amputee patients: An epidemiologic study. Arch Phys Med Rehabil. 1998;79(3):279-97. [PMID: 9523779]

19. Elixhauser A, Steiner C, Harris DR, Coffey RM. Comorbidity measures for use with administrative data. Med Care. 1998;36(1):8-27. [PMID: 9431328]

20. Deyo RA, Cherkin DC, Ciol MA. Adapting a clinical comorbidity index for use with ICD-9-CM administrative databases. J Clin Epidemiol. 1992;46(6):613-19. [PMID: 1607900]

21. Southern DA, Quan H, Ghali WA. Comparison of the Elixhauser and Charlson/Deyo methods of comorbidity measurement in administrative data. Med Care. 2000;42(4): 355-60. [PMID: 15076812]

22. Hanley JA, McNeil BJ. The meaning and use of the area under a receiver operating characteristic (ROC) curve. Radiology. 1982;143(1):29-36. [PMID: 7063747]

23. Hosmer DW, Lemeshow S. Applied logistic regression. New York (NY): John Wiley \& Sons; 1989.
24. Ford B. An overview of hot-deck procedures. In: Madow $\mathrm{W}$, Ingram $\mathrm{O}$, Nisselson $\mathrm{H}$, editors. Incomplete data in sample surveys. New York (NY): Academic Press; 1983. p. 185-207.

25. Collins TC, Johnson M, Daley J, Henderson WG, Khuri SF, Gordon HS. Preoperative risk factors for 30-day mortality after elective surgery for vascular disease in Department of Veterans Affairs hospitals: Is race important? J Vasc Surg. 2001;34(4):634-40. [PMID: 11668317]

26. Aulivola B, Hile CN, Hamdan AD, Sheahan MG, Veraldi JR, Skillman JJ, Campbell DR, Scovell SD, LoGerfo FW, Pomposelli FB Jr. Major lower extremity amputation: Outcome of a modern series. Arch Surg. 2004;139(4):395-99. [PMID: 15078707]

27. O’Hare AM, Feinglass J, Reiber GE, Rodriguez RA, Daley J, Khuri SF, Henderson WG, Johanson KL. Postoperative mortality after nontraumatic lower extremity amputation in patients with renal insufficiency. J Am Soc Nephrol. 2004; 15(2):427-34. [PMID: 14747390]

28. Kantonen I, Lepantalo M, Luther M, Salenius P, Ylonen K. Factors affecting the results of surgery for chronic critical leg ischemia-A nationwide survey. J Vasc Surg. 1998; 27(5):940-47. [PMID: 9620148]

29. Jencks SF, Williams DK, Kay TL. Assessing hospitalassociated deaths from discharge data. The role of length of stay and comorbidities. JAMA. 1988;260(15):2240-46. [PMID: 3050163]

30. Iezzoni LI, Foley SM, Daley J, Hughes J, Fisher ES, Heeren T. Comorbidities, complications, and coding bias. Does the number of diagnosis codes matter in predicting in-hospital mortality? JAMA. 1992;267(16):2197-2203. [PMID: 1556797]

31. Lavery LA, Van Houtum WH, Armstrong DG. Institutionalization following diabetes-related lower extremity amputation. Am J Med. 1997;103(5):383-88. [PMID: 9375706]

32. Ebskov LB. Relative mortality in lower limb amputees with diabetes mellitus. Prosthet Orthot Int. 1996;20(3): 147-52. [PMID: 8985993]

33. Duncan P, Studenski S, Richards L, Gollub S, Lai SM, Reker D, Perera S, Yates J, Koch V, Rigler S, Johnson D. Randomized clinical trial of therapeutic exercise in subacute stroke. Stroke. 2003;34(9):2173-80. [PMID: 12920254]

34. Stewart CP, Jain AS. Dundee revisited-25 years of a total amputee service. Prosthet Orthot Int. 1993;17(1):14-20. [PMID: 8337096]

35. Steinberg FU, Sunwoo I, Roettger RF. Prosthetic rehabilitation of geriatric amputee patients: A follow-up study. Arch Phys Med Rehabil. 1985;66(11):742-45. [PMID: 4062526]

36. Houghton AD, Taylor PR, Thurlow S, Rootes E, McColl I. Success rates for rehabilitation of vascular amputees: Implications for preoperative assessment and amputation level. Br J Surg. 1992;79(8):753-55. [PMID: 1393461] 
37. McWhinnie DL, Gordon AC, Collin J, Gray DW, Morrison JD. Rehabilitation outcome 5 years after 100 lower-limb amputations. Br J Surg. 1994;81(11):1596-99.

[PMID: 7827880]

38. Graham LA, Fyfe NC. Prosthetic rehabilitation of amputees aged over 90 is usually successful. Disabil Rehabil. 2002;24(13):700-701. [PMID: 12296985]

39. Scottish Intercollegiate Guidelines Network. Management of patients with stroke. Edinburg (Scotland): Royal College of Physicians; 1997.

40. Intercollegiate Working Party for Stroke. National clinical guidelines for stroke. London (England): Royal College of Physicians; 2000.
41. Stroke Unit Trialists' Collaboration. Organised inpatient (stroke unit) care for stroke. Cochrane Database Syst Rev. 2002(1):CD000197.

42. Post-Stroke Rehabilitation Guideline Panel. Post-stroke rehabilitation. Clinical practice guideline No. 16. Rockville (MD): U.S. Department of Health and Human Services, Public Health Service, Agency for Health Care Policy and Research; 1995.

Submitted for publication March 23, 2006. Accepted in revised form August 30, 2006. 